COMUNICAÇÃO CIENTÍFICA

\title{
PROTEÇÕES CONTRA QUEIMA SOLAR DE FRUTOS DE ABACAXIZEIRO SUBMETIDO A DIFERENTES LÂMINAS DE IRRIGAÇÃO ${ }^{1}$
}

\author{
OSDNÉIA PEREIRA LOPES ${ }^{2}$, VICTOR MARTINS MAIA³, SILVÂNIO RODRIGUES DOS SANTOS ${ }^{3}$, \\ GISELE POLETE MIZOBUTSI ${ }^{3}$, RODINEI FACCO PEGORARO ${ }^{3}$
}

RESUMO - O objetivo deste trabalho foi avaliar o uso de proteção contra queima solar e o efeito de diferentes lâminas de irrigação na qualidade dos frutos de abacaxizeiro 'Pérola'. O experimento foi conduzido na área experimental, no município de Janaúba-MG. O sistema de irrigação utilizado foi o gotejamentoe a quantidade de lâmina de irrigação aplicada foi calculada com base na evaporação do Tanque Classe-A(ECA). A proteção dos frutos contra queima solar foi realizada após o fechamento das últimas flores. O delineamento foi em blocos casualizados, segundo o esquema de parcelas subdivididas $5 \times 5$, tendo nas parcelas cinco lâminas de irrigação $(30 \%, 50 \%, 70 \%, 100 \%$ e $150 \%$ da ECA) e nas subparcelas 4 tipos de proteção: jornal, saco de papel marrom, TNT branco $\mathrm{n}^{\circ} 40$ e solução contendo cal a $10 \%$, além da testemunha, com quatro repetições. Avaliaram-se porcentagem de frutos com queima solar, firmeza, sólidos solúveis totais (SST), acidez total titulável (ATT), pH e relação SST/ATT da polpa. Os frutos protegidos com TNT apresentaram menor porcentagem de queima solar. A lâmina referente a 77 \% da ECA, associada à proteção com TNT ou com a cal proporcionam maiores valores de SST.

Termos para indexação: Ananas comosus var. comosus, 'Pérola', Qualidade.

\section{PROTECTION AGAINST SUNBURN OF PINEAPPLE FRUITS SUBMITTED TO DIFFERENT IRRIGATION LEVELS}

\begin{abstract}
The purpose of this study was to evaluate the use of solar protection against sunburn and the effect of different irrigation levels on fruit quality of pineapple 'Pérola'. The experiment was conducted in the experimental area in Janaúba, MG. The irrigation system used was drip and the amount of depth water applied was calculated based on the class-A evaporation pan (PAN). The protection of fruits against sunburn was made after floral closure. The design was randomized blocks, according to the split plots 5 $\mathrm{x} 4$, with five irrigation depth $(30 \%, 50 \%, 70 \%, 100 \%$ and $150 \%$ of PAN) and the subplots are 4 types of protections: newspaper, brown paper bag, TNT white $\mathrm{n}^{\circ} 40$ and lime solution $10 \%$ and the control, with four replications. It was evaluated the percentage of fruits with symptoms of sunburn, pulp firmness, total soluble solids (TSS), total titratable acidity (TTA), pH and TSS/TTA. Fruits protected with TNT showed a lower percentage of sunburn. The irrigation depth regarding $77 \%$ of PAN associated with TNT or lime protection resulted in higher TSS values.
\end{abstract}

Index terms: Ananas comosus var. comosus, Pérola, Quality.

1(Trabalho 273-13). Recebido em: 07-08-2013. Aceito para publicação em: 30-04-2014.

${ }^{2}$ Eng ${ }^{a}$. Agrônoma, M.Sc. em Produção Vegetal, Doutoranda em Fitotecnia da Universidade Federal de Viçosa. Departamento de Fitotecnia da Universidade Federal de Viçosa, 36570-000. neialopesp@ibest.com.br

${ }^{3}$ Eng $^{\circ}$. Agrônomo, D.Sc. Professor de Educação Superior da Universidade Estadual de Montes Claros, Campus de Janaúba-MG, Av. Reinaldo Viana 2630, Bico da Pedra, 39440-000. Bolsista BIPDT Fapemig. E-mails: victor.maia@unimontes.br; silvanio.santos@ unimontes.br; gisele.mizobutsi@unimontes.br; rodinei.pegoraro@unimontes.br 
Um dos problemas enfrentados pelos produtores de abacaxi, principalmente nas regiões tropicais, é a queima solar ou escaldadura do fruto que corresponde a uma anomalia de causa não parasitária ou não biológica, que pode causar perdas de até $70 \%$ na produção, a depender da época de colheita. Desta forma, é necessário que os frutos sejam protegidos, sobretudo em épocas de altas temperaturas e alta radiação solar (MATOS; CABRAL, 2004).

A queima solar, além de provocar alterações fisiológicas (CONTRERAS et al., 2008; FELICETTI; SCHARDER, 2009; FELICETTI; SCHARDER, 2009a; TARTACHNYK et al., 2011), torna os frutos impróprios para o consumo, perdendo assim seu valor comercial. Para reduzir os prejuízos causados pela queima solar, a utilização de técnicas agronômicas se faz necessária. A proteção, seja dos frutos, seja das plantas pode ser utilizada, com o objetivo de reduzir a incidência direta dos raios solares sobre os frutos (MATOS;CABRAL, 2004; AMARANTE et al., 2011). Porém, muitas vezes, não são utilizados materiais adequados para essa proteção, interferindo na qualidade final dos frutos.

Assim como a proteção de frutos, a irrigação também é uma prática de manejo importante para a cultura que, apesar de possuir necessidades hídricas relativamente baixas, quando comparada a outras frutíferas, apresenta demanda permanente de água, variável ao longo do ciclo e dependente de seu estádio de desenvolvimento (AZEVEDO et al., 2007). A irrigação realizada de forma eficiente, disponibilizando para a planta uma lâmina d'água adequada às suas necessidades hídricas, contribui para a melhoria das características qualitativas dos frutos (MELO et al., 2006).

O trabalho objetivou avaliar o uso de diferentes tipos de proteção contra queima solar bem como o efeito de lâminas de irrigação na qualidade dos frutos de abacaxi 'Pérola'.

$\mathrm{O}$ experimento foi conduzido em área experimental localizada no município de Janaúba, situado a $43^{\circ} 16^{\prime} 18,2^{\prime \prime} \mathrm{W}$ e $15^{\circ} 49^{\prime} 51,5^{\prime \prime} \mathrm{S}$ e altitude de aproximadamente $540 \mathrm{~m}$. A pluviosidade média da região é de aproximadamente $870 \mathrm{~mm}$, temperatura média de $24^{\circ} \mathrm{C}$, insolação de 2.700 horas anuais e clima Aw, tropical quente segundo a classificação de Köpen, apresentando inverno frio e seco. A água utilizada na irrigação apresentou $\mathrm{pH}$ de 7,3 e condutividade elétrica de 0,069 mmhos $\mathrm{cm}^{-1}$ e foi classificada sendo de baixo risco de salinização. A área experimental possui topografia plana, e o solo é de textura arenosa, sendo classificado como neossolo flúvico psamítico (EMBRAPA, 2006).

Foram utilizadas mudas da cultivar 'Pérola', com tamanho aproximado de $20 \mathrm{~cm}$ de comprimento. A cultura foi conduzida em fileira dupla, no espaçamento de $1,2 \times 0,4 \times 0,3 \mathrm{~m}$. Na adubação de plantio, foi utilizado, por planta, $4 \mathrm{~g} \mathrm{de} \mathrm{P}_{2} \mathrm{O}_{5}$ na forma de superfosfato simples e 15 gramas de FTE BR 12. Foram realizadas 14 adubações com nitrogênio e potássio, via água de irrigação, iniciando-se aos 90 dias após o plantio e finalizando 20 meses após. A ureia e o cloreto de potássio foram às fontes de nitrogênio e potássio, sendo aplicados 28 e 49 gramas por planta destes adubos, respectivamente. Além disso, foram realizadas 10 adubações foliares de sulfato de magnésio $(2 \%)$ e sulfato ferroso $(1 \%)$ entre o $5^{\circ}$ e o $18^{\circ}$ mês após o plantio.

O método de irrigação utilizado foi o gotejamento, com gotejadores autocompensantes de vazão nominal de $2,0 \mathrm{~L} \mathrm{~h}^{-1}$. O espaçamento entre os emissores foi de $0,25 \mathrm{~m}$ ao longo da linha lateral, sendo esta espaçada de 1,6 m, colocada a uma distância de $0,20 \mathrm{~m}$ das plantas. Foi determinado o coeficiente de uniformidade de aplicação que atingiu valores superiores a $92 \%$ em todas as parcelas.

O plantio foi realizado em março de 2008 , sendo que até o $7^{\circ}$ mês após o plantio, as irrigações foram feitas igualmente em todas as parcelas, visando a uniformizar o teor de água no solo para favorecer o crescimento inicial das mudas e o estabelecimento da cultura. A partir daí, foi iniciada a aplicação de diferentes lâminas de irrigação em dias alternados, sendo a quantidade de água calculada com base na evaporação do tanque Classe-A (ECA) instalado no local do experimento. A indução floral artificial foi realizada 20 meses após o plantio, e a proteção dos frutos, aos 60 dias antes da colheita.

O delineamento experimental utilizado foi em blocos casualizados, segundo o esquema de parcelas subdivididas $(5 \times 5)$, tendo nas parcelas cinco lâminas de irrigação, isto é, lâminas referentes a 30 \%, 50 \%, $70 \%, 100 \%$ e $150 \%$ da ECA, e nas subparcelas, a testemunha (sem proteção) e 4 tipos de proteções: jornal, saco de papel marrom, TNT branco $n^{\circ} 40$ e pincelamento de solução contendo cal hidratada na concentração de $10 \%$, totalizando 25 tratamentos e 4 repetições. Nas subparcelas, foram utilizadas quatro plantas úteis das 2 fileiras centrais, totalizando 20 plantas na parcela.

Os frutos foram colhidos quando havia pelo menos $50 \%$ da casca amarela. As características avaliadas foram: porcentagem de frutos queimados pelo sol, firmeza, $\mathrm{pH}$, sólidos solúveis totais (SST), acidez total titulável (ATT) e relação SST/ATT. A porcentagem de frutos queimados pelo sol foi obtida pela observação da presença ou ausência de queima nos frutos após a contagem. A firmeza dos frutos 
sem a casca foi obtida utilizando um penetrômetro de bancada marca Fruit Pressure Test FT 327, com resultados expressos em Newton (N). Para a determinação do $\mathrm{pH}$ da polpa foram utilizados $10 \mathrm{~g}$ da polpa triturada e homogeneizada com $90 \mathrm{~mL}$ de água destilada, sendo a leitura feita utilizando-se de pHmetro digital marca GEHAKA PG 1800. Os SSTs foram obtidos por refratometria, sendo os resultados expressos em ${ }^{\circ}$ Brix. A ATT foi determinada pela titulação da solução obtida a partir de 10 gramas da polpa triturada e homogeneizada com $90 \mathrm{~mL}$ de água destilada. Utilizou-se como titulante a solução de NAOH $0,2 \mathrm{~N}$, adicionandoà amostra três gotas de fenolftaleína a $1 \%$ como indicador. Os dados foram expressos em $\mathrm{mg}$ de ácido cítrico por $100 \mathrm{~g}$ de polpa. A relação SST / ATT foi obtida pela divisão dos valores de SST pelos valores de ATT.

Os dados foram interpretados por análises de variância e de regressão, para as lâminas de irrigação, e teste de Tukey, a $5 \%$ de probabilidade para os diferentes tipos de proteção de frutos. Os modelos da regressão adotados foram com base na significância dos coeficientes de regressão, utilizando-se o teste $\mathrm{t}$ de Student, até $10 \%$ de probabilidade, no coeficiente de determinação e no potencial para explicar o fenômeno biológico em questão. A análise estatística foi feita com auxílio SAEG V. 5.0.

A evaporação média do tanque Classe A (ECA), diária, durante o período de aplicação dos tratamentos, foi de $6,4 \mathrm{~mm}$, com uma reposição de $691,2 \mathrm{~mm} \mathrm{ano}^{-1}$ (30\% da ECA), $1.152 \mathrm{~mm}^{2} \mathrm{ano}^{-1}$ (50 $\%$ da ECA), 1.612,8 $\mathrm{mm} \mathrm{ano}^{-1}$ (70 \% da ECA), 2.304 $\mathrm{mm} \mathrm{ano}^{-1}$ (100\% da ECA) e $3.456 \mathrm{~mm} \mathrm{ano}^{-1}(150$ $\%$ da ECA), nos tratamentos referentes às lâminas de irrigação.

A maior média da porcentagem de queima entre os tratamentos aplicados foi observada na proteção com a cal, que foi observada alguns dias após o uso dos diferentes tipos de proteção do fruto (Tabela 1). Alguns fatores podem ter contribuído para este fato, como o ressecamento da casca do fruto pela cal devido à alta concentração de cálcio (10\%) utilizado na mistura, além do período de chuvas durante a condução do experimento que retirava a cal do fruto, sendo necessária, durante a condução do experimento, a reaplicação da cal por diversas vezes. Além disso, com o crescimento do fruto, a porção distal ficava exposta aos raios solares.

A aplicação da cal e a testemunha (sem proteção) proporcionaram maiores porcentagens de queima solar, correspondentes a 75 e $70 \%$ de frutos queimados, respectivamente, e as proteções com saco de papel e o TNT obtiveram médias inferiores, com 45 e $23 \%$ de frutos queimados (Tabela 1 ).
Os altos valores observados devem-se à alta intensidade luminosa característica da região do semiárido brasileiro que é ainda maior nos meses de verão, período este que compreendeu o desenvolvimento dos frutos. Os frutos que apresentaram sintomas externos de queima solar, em especial aqueles sem nenhuma proteção (testemunha), tornaram-se impróprios para o consumo, com lesões que comprometiam boa parte da polpa, indicando altos valores de perdas em função deste distúrbio.

Os frutos que foram protegidos com jornal apresentaram média de $46 \%$ de queima solar. Esta porcentagem de queima pode ter ocorrido em função da maior suscetibilidade dessa proteção aos ventos, sol e chuva que provocam sua retirada dos frutos ou sua deterioração.

O uso do saco de papel proporcionou média de $45 \%$ de frutos queimados. Este valor provavelmente se deve por ser um material vulnerável às condições climáticas que provocam seu ressecamento e destruição. Esse mesmo problema foi relatado por Pereira et al. (2009a) ao utilizar este material para o ensacamento da atemoia no qual apresentou menor resistência às condições climáticas com média de $56,7 \%$ de sacos rasgados

Os frutos que foram protegidos com TNT apresentaram valores de porcentagem de queima correspondentes a $23 \%$, sendo, portanto, bastante inferior à testemunha. Este fato deveu-se por esta proteção ter-se mantido intacta durante o experimento, evitando assim a exposição dos frutos aos raios solares. Otto et al. (2000) verificaram que o TNT diminui a radiação incidente, em média, de $20 \%$ do total que chega sobre o material quando trabalharam com espécies hortícolas. Destaca-se que qualquer sintoma de queima solar, independentemente da intensidade, foi considerado. Porém, observou-se que os frutos com sintomas de queima solar protegidos com TNT, jornal e saco de papel apresentavam menor intensidade de dano em relação àqueles da testemunha.

As médias dos teores de sólidos solúveis totais (SST), em função dos tipos de proteção, também podem ser observadas na Tabela 1. Notase que as maiores médias foram encontradas nos frutos submetidos à proteção com a cal $(18,10$ ${ }^{\circ}$ Brix), TNT (17,30 ${ }^{\circ}$ Brix) e saco de papel $(17,10$ o Brix), e as menores médias, com a proteção por jornal (16,20 ${ }^{\circ}$ Brix) e o tratamento-testemunha, ou seja, sem proteção (16,15 ${ }^{\circ}$ Brix). Euleuterio et al. (2010), trabalhando com ensacamento de bananas, observaram que o ensacamento com (PEBD + TNT) foi o que rendeu frutos com maior teor de sólidos totais. 
Apesar de os frutos submetidos à proteção com a cal apresentarem médias superiores de sólidos solúveis totais, vários autores que trabalharam com cálcio aplicado no fruto, na pré e pós-colheita, relatam que não observaram efeito significativo deste tratamento para o SST em relação às doses de cálcio aplicadas no fruto (PEREIRA et al., 2002; SILVA et al., 2008). Porém, a concentração de cálcio utilizada no experimento de $(10 \%)$ foi superior ao utilizado por esses autores que trabalharam com concentrações variando de 1 a 3\%. Todavia, Brackmann et al. (2010) observaram aumento do teor de sólidos solúveis totais em maçãs tratadas com cálcio em pré-colheita.

As médias dos teores de sólidos solúveis para as proteções contra queima solar em função da lâmina de 30\% e 70\% da ECA podem ser observadas na Tabela 2, não havendo efeito significativo para as demais lâminas avaliadas. A lâmina correspondente a $70 \%$ da ECA, associada à proteção com a cal, foi a que proporcionou médias superiores (19,5 $\left.{ }^{\circ} \mathrm{Brix}\right)$ de sólidos solúveis totais nos frutos, sendo o mesmo encontrado para a lâmina de $30 \%$ da $\operatorname{ECA}(18,5$ ${ }^{\circ}$ Brix), quando comparadas aos frutos submetidos à proteção com jornal e testemunha.

Os frutos protegidos com TNT apresentaram aumento nos valores de sólidos solúveis totais em função da lâmina de irrigação aplicada atingindo o máximo de $18,6^{\circ}$ Brix na lâmina correspondente a $77,9 \%$ da ECA. A partir deste ponto, observa-se redução nos valores de sólidos solúveis dos frutos protegidos com TNT (Figura 1). A redução dos SSTs com o aumento das lâminas pode ser explicada pelo provável aumento do conteúdo de água no fruto que promoveu a diluição dos SSTs.

Não houve efeito significativo dos tratamentos para as variáveis firmeza, $\mathrm{pH}$, Acidez Titulável e relação Brix/Acidez (Ratio) em função da proteção contra a queima solar, das lâminas de irrigação e da interação proteção de frutos e lâmina de irrigação. O mesmo foi encontrado por Faoro e Mondardo (2004) que não observaram influência na firmeza dos frutos de pereira ao utilizar o ensacamento. Todavia, Amarante et al. (2011) observaram redução nos valores de firmeza e sólidos solúveis totais em maçãs produzidas sob tela branca.

Para a variável firmeza, foi observada média de $8,96 \mathrm{~N}$, sendo valores diferentes dos citados por Pinheiro et al. (2005), que encontraram 7,6 N. Esta divergência possivelmente se deve em função de os frutos estarem menos maduros do que os avaliados por estes autores, estando assim mais firmes.

Para a variável $\mathrm{pH}$ da polpa foi encontrada média de 3,85. Esse valor corrobora os valores encontrados por Reinhardt et al. (2004) e Pinheiro et al. (2005), que obtiveram em seus trabalhos médias de 3,89 e 3,82, respectivamente. A variável ATT apresentou média de 1,07 de ácido cítrico por 100 $\mathrm{g}$ de polpa. Essa média é superior à encontrada em Reinhardt et al. (2004), com valor de 0,45, por Souto et al. (2010) de 0,71 e por Maeda et al. (2011) de 0,88 de ácido cítrico por $100 \mathrm{~g}$ de polpa. A relação SST/ATT média obtida foi de 17,20. Esta relação corresponde ao balanço entre a doçura e a acidez. No presente trabalho a ATT foi relativamente alta, o que contribuiu para menor média da relação SST/ ATT quando comparada a observações de outros autores (PEREIRA et al., 2009; SOUTO et al., 2010).

As proteções contra queima solar e as lâminas de irrigação utilizadas não influenciaram na firmeza, acidez total titulável, $\mathrm{pH}$ e relação brix/acidez da polpa. Porém a proteção com TNT branco $n^{\circ} 40$ reduz a queima solar do abacaxi 'Pérola'. Além disso, os frutos protegidos com TNT branco $n^{\circ} 40$, produzidos a partir de plantas submetidas à lâmina de $77 \%$ da ECA, possuem maiores valores de sólidos solúveis totais. 
TABELA 1 - Porcentagem de frutos queimados (PFQ) e sólidos solúveis totais (SST) dos frutos de abacaxizeiro 'pérola' em função dos tipos de proteção contra queima solar.

\begin{tabular}{lcc}
\hline \multicolumn{1}{c}{ Proteções } & PFQ $(\%)$ & SST $\left({ }^{\circ}\right.$ Brix $)$ \\
\hline Testemunha & $70 \mathrm{ab}$ & $16,15 \mathrm{~b}$ \\
Jornal & $46 \mathrm{bc}$ & $16,20 \mathrm{~b}$ \\
Saco de papel & $45 \mathrm{c}$ & $17,10 \mathrm{a}$ \\
TNT & $23 \mathrm{c}$ & $17,30 \mathrm{a}$ \\
$\mathrm{Cal}$ & $75 \mathrm{a}$ & $18,10 \mathrm{a}$ \\
\hline
\end{tabular}

*Médias seguidas pela mesma letra na coluna não diferem entre si, pelo teste de Tukey, a $5 \%$ de probabilidade.

TABELA 2 - Sólidos Solúveis Totais (SST) dos frutos de abacaxizeiro 'pérola' para as proteções contra queima solar em função das lâminas de $30 \%$ e $70 \%$ da ECA

\begin{tabular}{lcc}
\hline \multicolumn{1}{c}{ Proteções } & $30 \%($ ECA $)$ & $70 \%($ ECA $)$ \\
\hline Testemunha & $15,7 \mathrm{~b}$ & $16,0 \mathrm{~b}$ \\
Jornal & $15,25 \mathrm{~b}$ & $15,7 \mathrm{~b}$ \\
Saco de papel & $17,7 \mathrm{ab}$ & $17,7 \mathrm{ab}$ \\
TNT & $17,5 \mathrm{ab}$ & $17,5 \mathrm{ab}$ \\
Cal & $18,5 \mathrm{a}$ & $19,5 \mathrm{a}$ \\
\hline
\end{tabular}

*Médias seguidas pela mesma letra na coluna não diferem entre si, pelo teste de Tukey, a $5 \%$ de probabilidade.

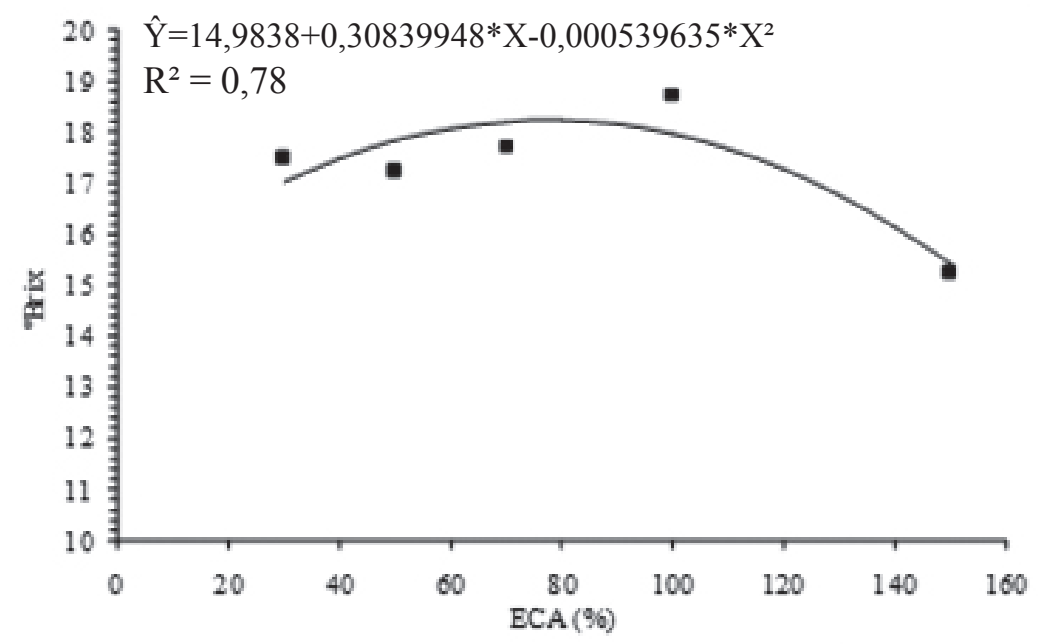

*Significativo ao nível de $5 \%$ de probabilidade, pelo teste t.

FIGURA 1 - Sólidos solúveis totais ( $\left({ }^{\circ}\right.$ Brix $)$ dos frutos protegidos com TNT e plantas submetidas a diferentes lâminas de irrigação. 


\section{AGRADECIMENTOS}

À Fundação de Amparo à Pesquisa do Estado de Minas Gerais (FAPEMIG), ao Conselho Nacional de Desenvolvimento Científico e Tecnológico (CNPq) e à Coordenadoria de Aperfeiçoamento de Pessoal de Nível Superior (CAPES), pela concessão de bolsas e apoio financeiro.

\section{REFERÊNCIAS}

AMARANTE, C. V. T.; STEFFENS, C. A.; ARGENTA, L. C. Yield and fruit quality of 'Gala' and 'Fuji' apples trees protected by anti-hail net. Scientia Horticulturae, Amsterdam, v. 129, p. 7985,2011 .

AZEVEDO, P. V.; SOUZA, C. B.; SILVA, B. B.; SILVA, V. P. R. Water requeriments of pineapple crop grown in a tropical environment, Brazil. Agricultural Water Management, Amsterdam, v. 88, p. 201-208, 2007.

BRACHMANN, A.; SCHOOR, M. R. W.; PINTO, J. A. V.; VENTURINI, T. L. Aplicação pré-colheita de cálcio na qualidade pós-colehita de maçãs 'fuji'. Ciência Rural, Santa Maria, v. 40, n. 6,p. 14351438, 2010.

CONTRERAS, C.; ZOFFOLI, J. P.; ALCADE, J. A.; AYALA, M. Evolución del daño por insolación de manzanas 'granny smith' durante el almacenaje refrigerado. Ciência e Investigación Agraria, Santiago, v. 35, n. 2, p. 147-157, 2008.

EMBRAPA - Empresa Brasileira de Pesquisa Agropecuária - Centro Nacional de Pesquisa de Solos. Sistema brasileiro de classificação de solos. 2.ed. Rio de Janeiro, 2006. 306p.

EULEUTERIO, M. D.; GIOPPO, M.; SOZIM, M.; MALGARIM, M. B. Avaliação das características fisico-químicas de bananas- prata (musa AAB subgrupo prata) ensacadas em diferentes tipos de materiais. Revista de Engenharia e Tecnologia, Ponta Grossa, v.2, n.1, 2010.

FAORO, I. D.; MONDARDO, M. Ensacamento de frutos de pereira cv. Housui. Revista Brasileira de Fruticultura, Jaboticabal, v.26, n.1, p.86-88, 2004.
FELICETTI, D.; SCHARDER, L. E. Changes in pigment concentrations associated with sunburn browning on five apples cultivars. I. Chlorophylls and carotenoids. Plant Science, Limerick, v.176, p. 78-83, 2009.

FELICETTI, D.; SCHARDER, L. E. Changes in pigment concentrations associated with sunburn browning on five apples cultivars. II. Phenolics. Plant Science, Limerick, v.176, p.84-89, 2009a.

MAEDA, A. S.; BUZZETTI, S.; BOLIANI, A. C.; BENETT, C. G. S.; TEIXEIRA FILHO, M. C. M.; ADREOTTI, M. Foliar fertilization on pineapple quality and yield. Pesquisa Agropecuária Tropical, Goiânia, v.41, n.2, p.248-253, 2011.

MATOS, A. P.; CABRAL, J. R. S. Queima solar do fruto do abacaxizeiro e seu controle. 2004. Disponível em: <http://www.cnpmf.embrapa.br/ publicacoes/produto_em_foco/abacaxi_27.pdf $>$. Acesso em: 10 abr. 2013.

MELO, A. S.; NETTO, A. O.; DANTAS NETO, J.; BRITO, M. E. B.; VIÉGAS, P. R. A.; MAGALHÃES, L. T. S.; FERNANDES, P. D. Desenvolvimento vegetativo, rendimento da fruta e otimização do abacaxizeiro cv. Pérola em diferentes níveis de irrigação. Ciência Rural, Santa Maria, v.36, n.1, p.93-98, 2006.

OTTO, R. F.; GIMENEZ, C.; CASTILlA, N. Modificações microclimáticas sob proteção de polipropileno cultivado com espécies hortícolas em Córdoba, Espanha. Horticultura Brasileira, Brasília, v.18, n. 3, p. 204-211, 2000.

PEREIRA, A. J.; BLANK, A. F.; ALVARENGA, M. A. R.; SOUZA, R. J. Aplicação de fontes e doses de cálcio na produção e qualidade de frutos de melão. Horticultura Brasileira, Brasília, v. 20, n. 3, p. 428-431, 2002.

PEREIRA, M. A. B.; SIEBENEICHLER, S. C.; LORENÇON, R.; ADORIANI, G. C.; SILVA, J. C.; GARCIA, R. B. M.; PEQUENO, D. N. L.; SOUZA, C. M.; BRITO, R. F. F. Qualidade do fruto de abacaxi comercializado pela cooperfruto - miranorte - TO. Revista Brasileira de Fruticultura, Jaboticabal, v. 31, n. 4, p.1048-1053, 2009. 
PEREIRA, M. C. T.; BANDEIRA, N.; ANTUNES JÚNIOR, R. C.; NIETSCHE, S.; OLIVEIRA JÚNIOR, M. X.; ALVARENGA, C. D.; SANTOS, T. M.; OLIVEIRA, J. R. Efeito do ensacamento na qualidade dos frutos e na incidência da brocados-frutos da atemoieira e da pinheira. Bragantia, Campinas, v.68, n.2, p.389-396, 2009a.

PINHEIRO, A. C. M.; BOAS, E. V. B.; LIMA, L. C. Influência do $\mathrm{CaCl}_{2}$ sobre a qualidade pós-colheita do abacaxi cv. Pérola. Ciência tecnologia de alimentos, Campinas, v.25, n.1, p.32-36, 2005.

REINHARDT, D. H.; MEDINA, V. M.; CALDAS, R. C.; CUNHA, G. A. P.; ESTEVAM, R. F. H. Gradientes de qualidade em abacaxi 'pérola' em função do tamanho e do estádio de maturação do fruto. Revista Brasileira de Fruticultura, Jaboticabal, v.26, n.3, p.544-546, 2004.
SILVA, J. D.; CHOUDHURY, M. M.; MENDES, A. M. S.; DANTAS, B. F. Efeito da aplicação précolheita de cálcio na qualidade e no teor de nutrientes de manga 'Tommy Atkins. Revista Brasileira de Fruticultura. Jaboticabal, v.30, n.1, p.74-78, 2008.

SOUTO, R. F.; DURIGAN, J. F.; SANTOS, L. O.; SOUZA, B. S.; MENEGUCCI, J. L. P. Características químicas de abacaxi 'pérola' após tratamento com calor e armazenagem em três temperaturas. Revista Brasileira de Fruticultura, Jaboticabal, v.32, n.1, p.047-056, 2010.

TARTACHNYK, I.; KUCKENBERG, J.; YURI, J. A.; NOGA, G. Identifying fruit characteristics for non-invasive detection of sunburn in apple. Scientia Horticulturae, Amsterdam, v.134, p.108-113, 2012. 